\title{
Retrofit of Control Active Roll Damping System at KRI RUPAT 712 using PLC OMRON CJ2M CPU 31
}

\author{
Surawan Setiyadi \\ Study Program of Electrical Engineering, Faculty of Engineering, President University \\ Jl. Ki Hajar Dewantara, Cikarang Baru, Bekasi-17550, Indonesia \\ Corresponding author: surawan@president.ac.id
}

\begin{abstract}
Minesweeper Warship KRI Pulau Rupat 712 needs stability when sails at the sea. Stability control system has had some problems due to their electronic life time equipment, remembering that this ship was made by Holland in 1984 (more than 30 years ago). Rejuvenation of control system is needed in order that its stability system is still can be functioned. Current control system use electronics card which is rather difficult to be repaired when it is broken. PLC is one of the solutions to change the electronics card system because PLC is easy to install and using programming system which is also easy to learn and having been used by a lot of industry likes automotive, food and beverage, oil and gas, textile, and etc. Some of the old instruments still can be used because PLC can support them, except there are few instruments that must be changed and added, for example: must change the gyro sensor and add the soft button HMI to change the hard button.
\end{abstract}

Keywords: PLC, HMI, Gyro Sensor

\begin{abstract}
ABSTRAK
Kapal Perang Penyapu Ranjau KRI Pulau Rupat 712 membutuhkan kestabilan pada saat berlayar dilaut. Perangkat elektronik sistem kendali kestabilan yang ada sudah mulai mengalami kerusakan dikarenakan termakan oleh usia mengingat kapal perang ini buatan negeri Belanda pada tahun 1984 (lebih dari 30 tahun lalu). Peremajaan sistem kendali diperlukan agar kapal ini masih bisa difungsikan sistem kestabilannya. Sistem kendali yang ada menggunakan kartu elektronik yang relatif sulit untuk diperbaiki jika terjadi kerusakan pada sistem pengendalinya. PLC sebagai salah satu solusi untuk menggantikan sistem pengendali menggunakan electronics card, karena PLC sangat mudah dipasang dan menggunakan sistem pemrograman yang mudah dipelajari serta sudah banyak digunakan pada dunia industri otomotif, makanan dan minuman, minyak dan gas, tekstil dsb. Instrumen-instrumen yang sudah ada sebelumnya sebagian masih bisa digunakan karena masih bisa didukung oleh PLC kecuali ada beberapa bagian instrument yang harus diganti dan ditambahkan misalnya penggantian gyro sensor dan penggantian operator panel dari tombol keras menjadi tombol lunak menggunakan HMI.
\end{abstract}

Kata Kunci: PLC, HMI, Gyro Sensor

\section{INTRODUCTION}

Kapal perang KRI Rupat 712 milik TNI Angkatan Laut Republik Indonesia merupakan kapal yang digunakan untuk menyapu ranjau buatan Negara Belanda tahun 1984. Kapal ini mempunyai sistem kestabilan untuk menjaga keseimbangan kapal pada saat kapal terhantam oleh ombak laut. Sudah hampir 10 tahun sistem kestabilan kapal ini sudah tidak berfungsi sebagaimana mestinya dikarenakan komponen yang digunakan sudah mulai rusak dan tidak berfungsi. Atau dapat dikatakan bahwa sistem kestabilan kapal ini sudah tidak berfungsi sama sekali sehingga pada saat digunakan maka kapal tidak mampu menstabilkan posisi jika dihantam oleh ombak gelombang laut. Maka diperlukan perbaikan pada sistem kestabilan mengingat kapal ini merupakan salah satu alutsista milik TNI AL yang masih digunakan sampai dengan saat ini.

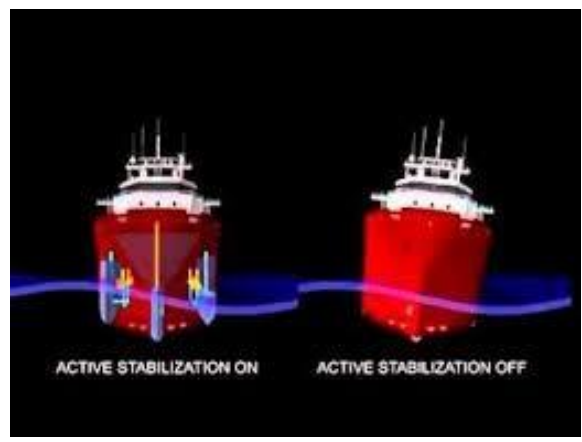

Gambar 1. Active Roll Damping System 


\section{SURVEy AND ANALYSIS}

Dari survei dan analisa yang dilakukan didapatkan sistem sudah tidak berfungsi lagi atau dalam kondisi mati total. Pengecekan awal dilakukan ke perangkat master controller, dimana ditemukan power source ke master controlller dalam kondisi tidak bisa dihidupkan. Beberapa komponen listrik tidak berfungsi dan dalam kondisi sudah terlepas dari tempatnya. Hampir seluruh relai dalam kondisi hilang pada tempatnya. Sensor-sensor sebagai masukan informasi safety pada hydraulic power pack mengalami kerusakan yang cukup parah, dimana seluruh solenoid valve dan manometer dalam keadaan tidak berfungsi. Sensor operculum position yang dalam hal ini menggunakan potensiometer tidak berfungsi, demikian juga untuk mengetahui ketinggian bahan bakar menggunakan sensor model batang atau stick juga tidak berfungsi. Gyro sensor yang digunakan untuik mengetahui kemiringan kapal dalam keadaan tidak berfungsi.

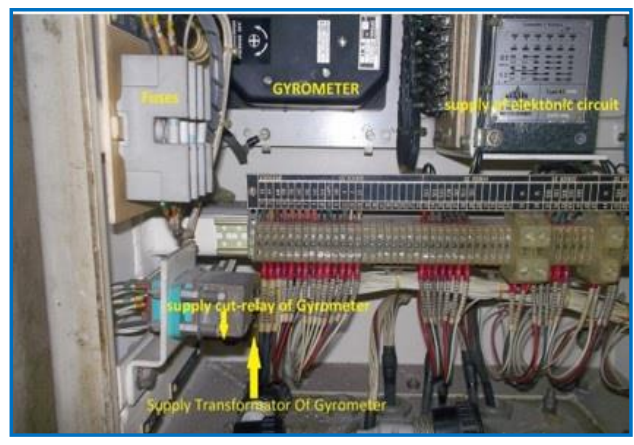

Gambar 2. Kondisi Master Controller

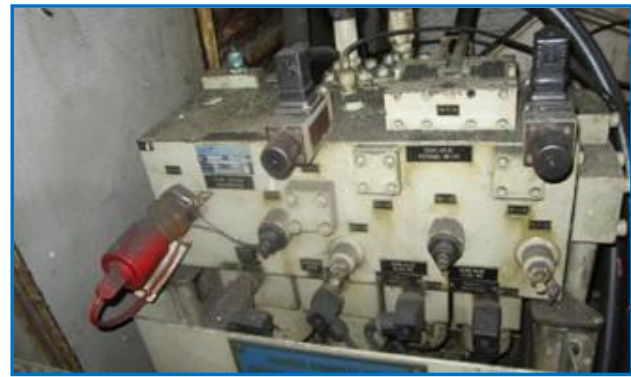

Gambar 3. Kondisi power pack dan solenoid valve

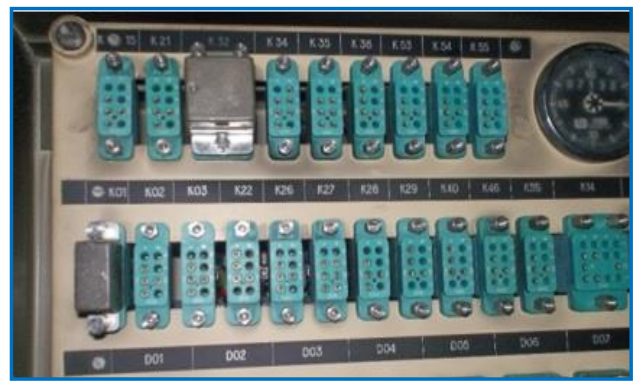

Gambar 4. Kondisi Relai Tidak Lengkap

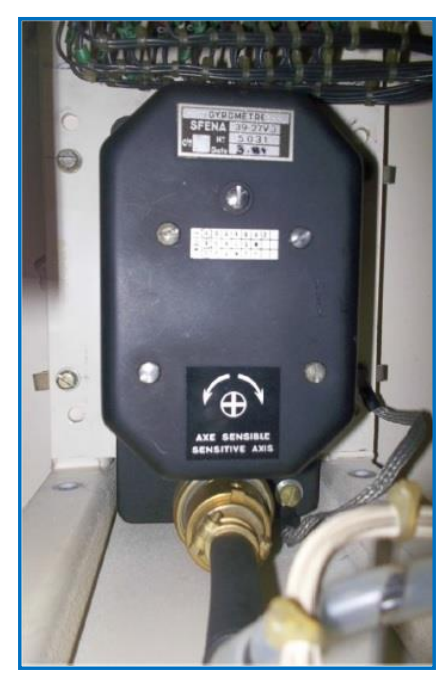

Gambar 5. Kondisi Gyro Sensor

\section{METHOD}

Untuk nendapatkan hasil yang diinginkan maka metode yang dipakai adalah dengan metode literature dan rekayasa melalui retrofit sistem kontrol.

\subsection{Metode Literatur}

Mencari materi yang berkaitan dengan pengganti master controller yaitu dengan Programmable Logic Controller (PLC), pengganti operator panel dengan Human Machine Interface (HMI), encoder sebagai pendeteksi posisi operculum, solenoid valve, gyro sensor, level sensor.

\subsection{Metode Rekayasa dan Retrofit}

Melakukan perancangan dan kemudian melakukan serangkaian simulasi dan retrofit yang dilanjutkan dengan pengujian dan percobaan di lapangan.

\section{LITERATURE REVIEW}

Dalam melakukan perancangan alat pada penelitian ini diperlukan pengetahuan tentang PLC, HMI, solenoid valve, gyro sensor, level sensor, encoder, operculum untuk mendukung dalam melakukan retrofit.

\subsection{Master Controller}

Master controller yang terpasang pada unit stabilizer kapal saat ini terdapat card yang berupa Printed Circuit Board (PCB) sebagai pengolah data. Semua informasi dari level sensor untuk mengetahui posisi cairan penyeimbang kapal, pressure switch sebagai pengaman power pack dan gyro sensor mengetahui posisi kemiringan kapal akan diolah oleh master controller yang 
berfungsi memerintahkan operculum sebagai penyeimbang posisi kapal.

Dikarenakan kondisi master controller pada saat dilakukan survei kondisinya sudah tidak bisa dipakai maka sebagai penggantinya menggunakan PLC.

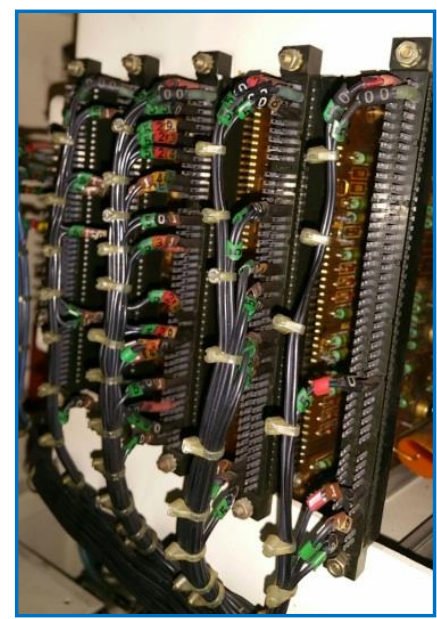

Gambar 6. Main Board Master Controller

\subsection{Programmable Logic Controller}

Programmable Logic Controller (PLC) adalah komputer elektronik yang mudah digunakan (user friendly) berfungsi mengolah nilai masukan ON dan OFF maupun nilai yang bervariasi (analog) yang diumpankan ke keluaran yang berupa kondisi ON dan OFF maupun nilai yang beravarisi (analog). [2]

Sekilas tentang PLC, sbb:

a. Programmable, menunjukkan kemampuan dalam hal memori untuk menyimpan program yang telah dibuat yang dengan mudah diubahubah fungsi atau kegunaannya.

b. Logic, menunjukkan kemampuan dalam memproses input secara aritmatika dan logika, yaitu melakukan operasi membandingkan, menjumlahkan, mengalikan, membagi, mengurangi, negasi, AND, OR, dan lain sebagainya.

c. Controller, menunjukkan kemampuan dalam mengontrol dan mengatur proses sehingga menghasilkan keluaran yang diinginkan.

Pengolahan data masukan, yang di terima dari gyro sensor dan encoder oleh PLC akan dihitung, hingga menghasilkan keluaran / perintah untuk menentukan pergerakan operculum.

PLC akan menentukan arah pergerakan operculum, apakah ke kiri atau ke kanan dan juga jarak yang harus di tempuh hingga tercapai stabilitas yang baik, berdasarkan sinyal dari gyro sensor.

PLC akan di lengkapi juga informasi error atau alarm, yang akan di tampilkan melalui HMI. Antara lain kondisi posisi operculum, posisi gyro sensor, alarm pada semua sensor dan alarm pada sistem hidrolik.

PLC yang digunakan adalah PLC dengan merk OMRON dari keluarga CJ2M CPU31 seperti terlihat pada gambar di bawah ini.

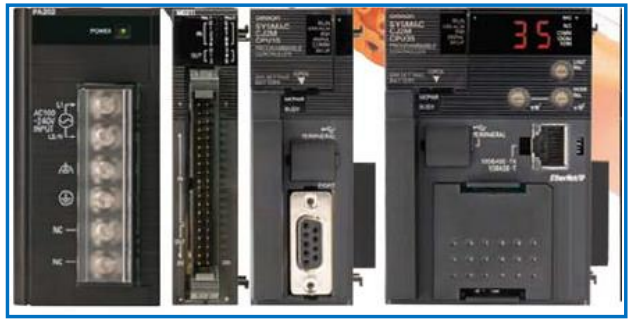

Gambar 7. PLC OMRON CJ2M CPU31

\subsection{Human Machine Interface}

Human Machine Interface (HMI) adalah peralatan yang berfungsi sebagai monitoring data, pengganti hard button maupun indicator yang terintegrasi dalam satu layer [4]. Operator Panel (OP) yang terpasang saat ini masih menggunakan sistem yang konvensional. HMI akan dipasang sebagai pengganti OP yang masih konvensional. Peralatan HMI ini bisa memberikan informasi yang lebih jelas dan lengkap antara lain:

a. Start \& Stop system.

b. Posisi kapal yang di deteksi oleh gyro sensor.

c. Posisi opercullum yang di deteksi oleh encoder.

d. Alarm pada hydraulic system dan error position opercullum.

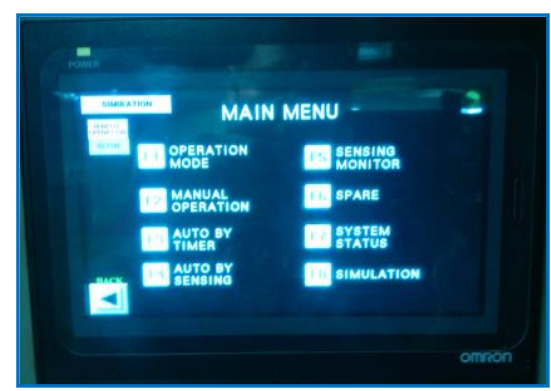

Gambar 8. HMI Omron NB Series

\subsection{Gyro Sensor}

Gyro sensor adalah alat untuk mendeteksi kondisi kemiringan kapal. Dengan sensor ini sistem dapat mengetahui kondisi nilai kemiringan kapal yang menghasilkan keluaran dengan tipe analog. Data analog dari gyro sensor akan di proses oleh PLC untuk menghasilkan keluaran ke sistem operculum dan transfer pump yang berguna untuk meyeimbangkan posisi kapal sebagai stabilizer system. 


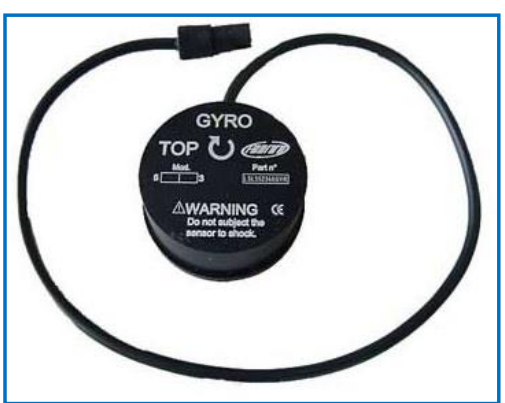

Gambar 9. Gyro Sensor Pengganti

Tipe keluaran sinyal yang di gunakan adalah analog signal dengan keluaran nilai 4-20mA. Berikut karakteristiknya ditampilkan dalam gambar 10 di bawah ini.

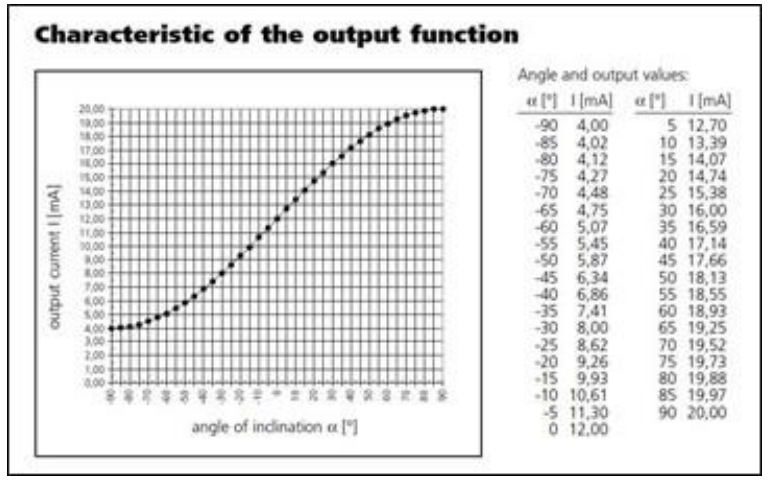

Gambar 10. Karakteristik Gyro Sensor

\subsection{Encoder}

Potesiometer sebagai pendeteksi posisi operculum digantikan oleh encoder. Jika sebelumnya potensiometer bekerja berdasarkan sebagai pembagi tegangan, maka sekarang potensiometer tersebut digantikan oleh encoder. Encoder memberikan keluaran pulsa dan kemudian pulsa tersebut diolah oleh PLC sebagai posisi operculum berada. Jika pendeteksi posisi masih menggunakan potensiometer, maka dibutuhkan analog card pada PLC sedangkan jika menggunakan encoder maka yang dibutuhkan adalah digital input card pada PLC. Macam encoder ada dua yaitu Absolute Encoder dan Incremental Encoder [4]. Encoder yang digunakan di sini adalah Incremental Encoder dengan merek OMRON [7].
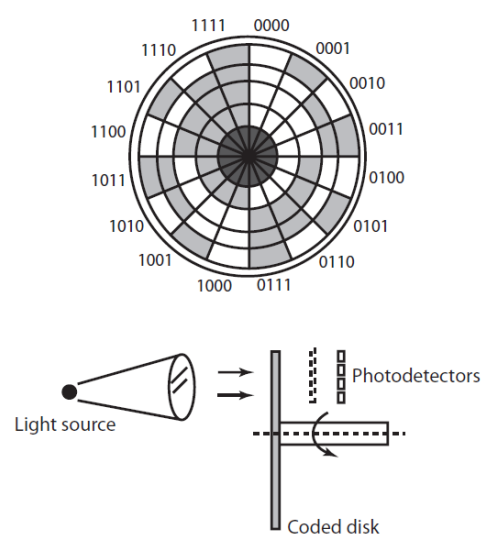

Gambar 11. Bagian Dalam Encoder

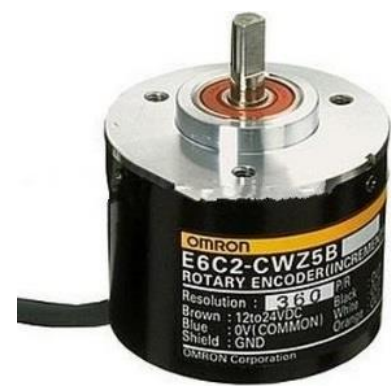

Gambar 12. Encoder OMRON

\subsection{Operculum}

Operculum yang terpasang di kapal ini adalah sebuah hydraulic cylinder yang berfungsi sebagai penyeimbang kapal jika kapal terhantam oleh ombak [3]. Digerakkan oleh solenoid valve, dimana solenoid valve tersebut akan bekerja berdasarkan kemiringan kapal yang dideteksi oleh gyro sensor. Untuk sistem kerja operculum dapat dilihat pada diagram hydraulic system di bawah ini. [1]

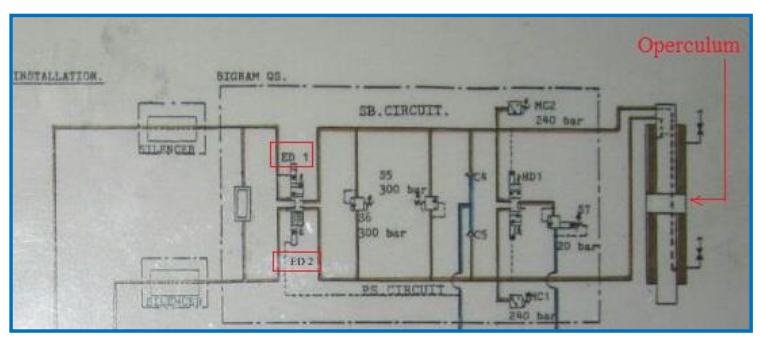

Gambar 13. Operculum Hydraulic Diagram 


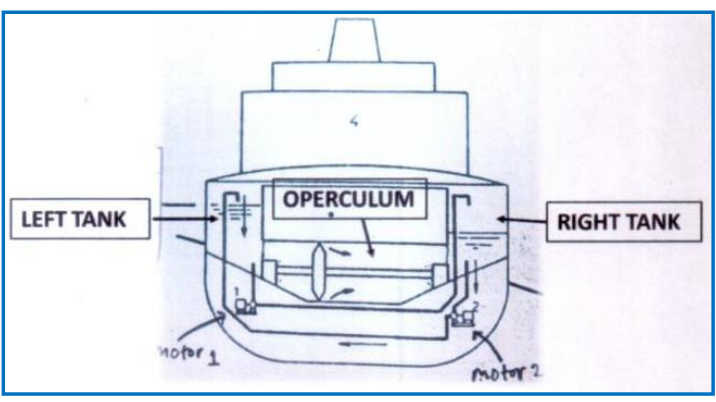

Gambar 14. Operculum Pada Kapal

\section{Design Of StabiLIZER System}

Rancangan sistem KRI Rupat 712 seperti terlihat pada alir diagram di bawah ini:

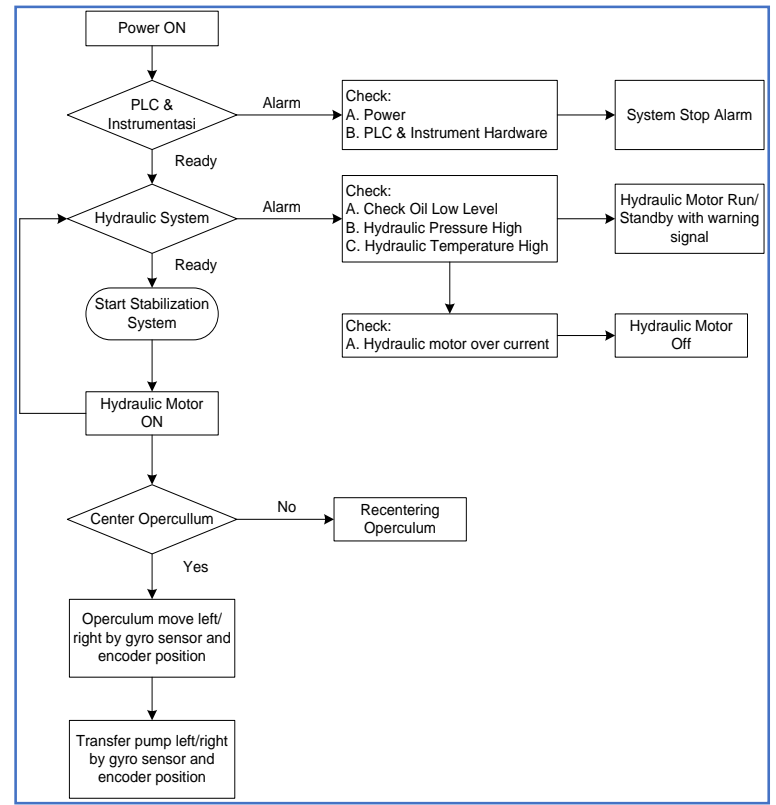

Gambar 15. Diagram Alir Rancangan Stabilizer System berikut:

Dari diagram alir di atas dapat dijelaskan sebagai

$\checkmark \quad$ Sesaat setelah sumber tegangan dihidupkan maka memberikan sumber daya ke beberapa alat instrumentasi yaitu: $C P U$ PLC, encoder operculum position, sensor for centering operculum, left and right limit sensor operculum, oil level sensor.

$\checkmark \quad$ Jika terjadi kesalahan salah satu atau lebih dari alat instrumentasi tersebut maka PLC memberikan peringatan alarm dan mematikan sistem.

$\checkmark$ Jika alat instumentasi dalam kodisi tidak ada masalah maka dilanjutkan dengan menghidupkan sistem hidrolik. Setelah sistem hidrolik dihidupkan dilanjutkan dengan pengecekan hydraulic oil level, hydraulic high pressure dan hydraulic high temperature. Jika ada masalah maka dilanjutkan dengan sistem alarm pada hidrolik dan mematikan motor hidrolik. Selanjutnya jika tidak ada masalah pada sistem hidrolik maka dilanjutkan dengan menghidupkan stabilizer system.

$\checkmark$ Setelah stabilizer system dihidupkan maka encoder pada operculum melihat posisi operculum apakah sudah berada pada posisi tengah ataukah belum. Jika posisi operculum belum pada posisi tengah maka hidrolik memerintahkan operculum ke arah kiri atau kanan sampai operculum pada posisi tengah ditandai dengan lampu indikator posisi tengah operculum menyala.

Selanjutnya stabilizer system bekerja berdasarkan posisi gyro sensor. Jika posisi kapal miring ke kiri atau ke kanan, gyro sensor mendeteksi sudut kemiringannya dan segera memerintahkan hidrolik untuk menggerakkan posisi operculum untuk menyeimbangkan posisi kapal. Sebagai contoh gyro sensor mendeteksi kapal miring ke kiri, maka dengan segera operculum bergerak ke kanan untuk mendorong bahan bakar dan dibantu oleh transfer pump supaya bahan bakar berada pada sebelah kanan kapal sehingga kapal tidak miring ke sebelah kiri. Demikian pula sebaliknya jika gyro sensor mendeteksi kemiringan posisi ke arah kanan, maka tugas operculum dan transfer pump menyeimbangkan posisi kapal.

\section{INSTRUMENT TEST}

Langkah berikutnya adalah pengujian alat setelah dilakukan retrofit. Berikut ini adalah beberapa bagian retrofit yang sudah dilakukan yaitu: bagian master control, bagian relay, bagian panel operator.

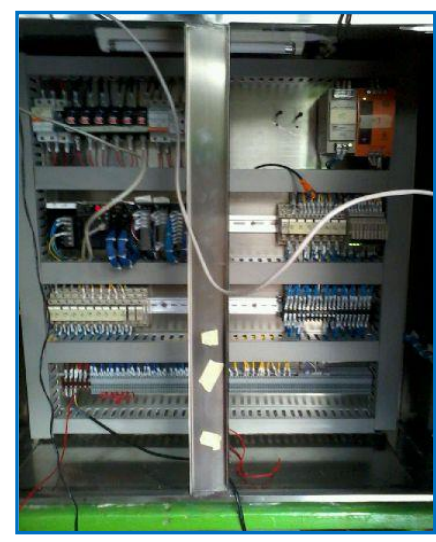

Gambar 16. Bagian Master Control 


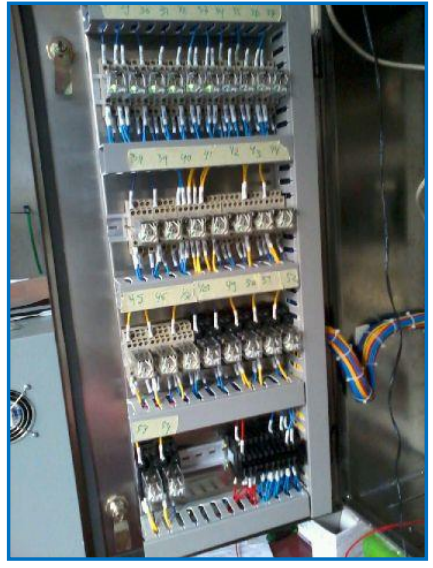

Gambar 17. Bagian Relay pada Master Control

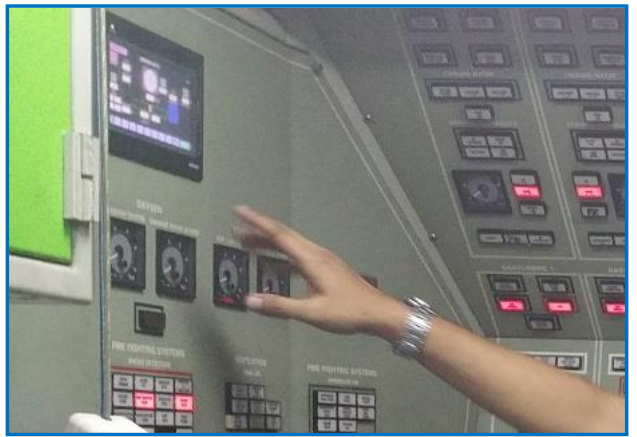

Gambar 18. Bagian Panel Operator

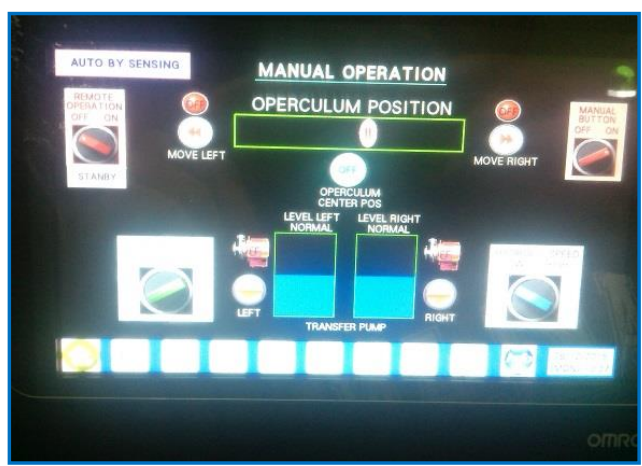

Gambar 19. Salah Satu Menu Pada Panel Operator

Saat sistem sudah normal dan "Auto Start" dijalankan maka hydraulic motor bekerja dan operculum akan bekerja sesuai dengan posisi gyro sensor. Dari percobaan dilakukan posisi gyro sensor yang dimainkan berdasarkan tabel berikut:

Tabel 1. Data Percobaan Posisi Gyro Sensor

\begin{tabular}{|l|l|l|}
\hline $\begin{array}{c}\text { Posisi Gyro } \\
\text { sensor }\end{array}$ & $\begin{array}{c}\text { Angka } \\
\text { konversi ke } \\
\text { PLC }\end{array}$ & Pergerakan Operculum \\
\hline$-5^{0}$ & 1900 & Move Right \\
\hline $5^{0}$ & 2100 & Move Left \\
\hline
\end{tabular}
ini: [6]

Dari tabel bisa dilihat pada diagram ladder PLC berikut

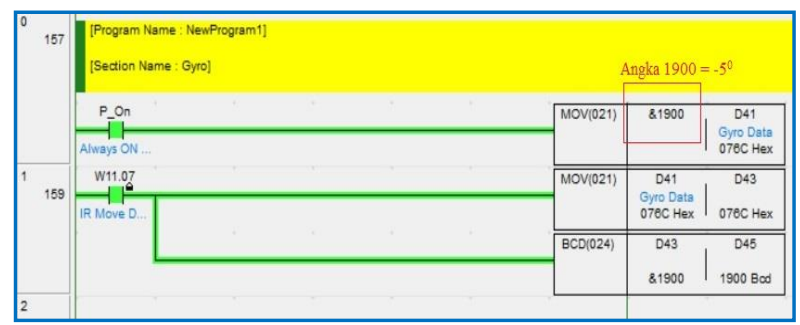

Gambar 20. Posisi Kapal pada Sudut Kemiringan $-5^{0}$

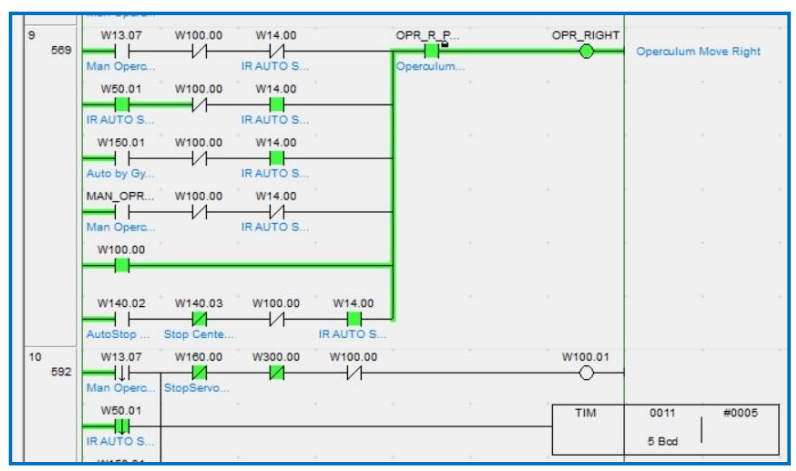

Gambar 21. Pergerakan Operculum ke Kanan

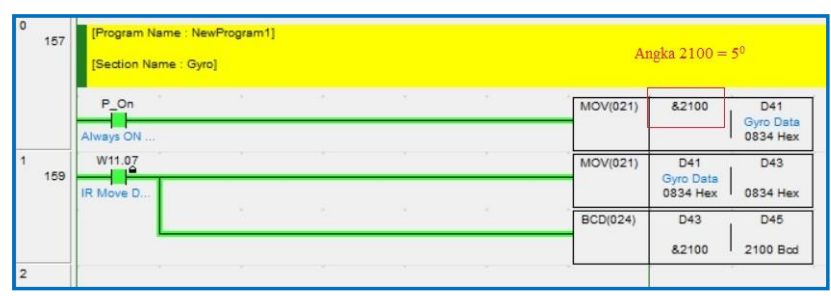

Gambar 22. Posisi Kapal pada Sudut Kemiringan $5^{0}$

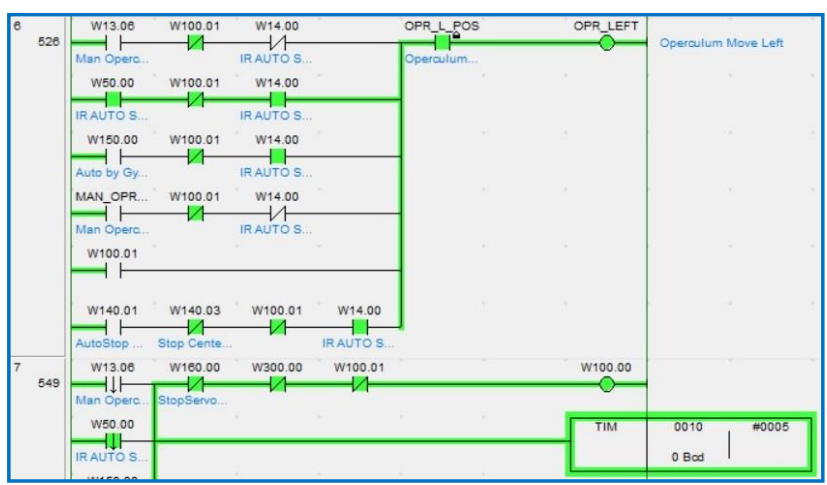

Gambar 23. Pergerakan Operculum ke Kiri 


\section{ConClusions AND Future DEVELoptMENTS}

6.1 Kesimpulan

a. Pengendali sistem kestabilan kapal dapat diganti dengan PLC. PLC ini sebenarnya banyak digunakan untuk keperluan pengendali mesin-mesin di industri otomotif, makanan, minuman, tekstil, oil and gas dll dan jarang dipakai untuk sistem pengendali kapal.

b. Instrument asli dari kapal dapat digantikan dengan instrument lain sepanjang instrument tersebut cara kerjanya tidak mempengaruhi sistem sebelumnya. Misalnya penggantian potensiometer pada untuk mengetahui posisi operculum digantikan dengan encoder.

\subsection{Saran}

Solenoid valve yang digunakan pada pengendali operculum masih menggunakan sistem ON-OFF sehingga untuk mengatur kecepatan masih secara manual, sebaiknya ditambahkan solenoid valve yang bisa di atur kecapatannya secara elektrik dan otomatis yaitu menggunakan proportional valve.

\section{REFERENCES}

[1] Ship's Stabilising Installation RUPAT 712, pp. 1.4.6/7.4

[2] OMRON User's Manual, CJ2M CPU Unit Pulse I/O Module, Japan 2010

[3] Active Roll Damping Manual Book, 1984

[4] OMRON Programmable Terminals NB-Designer Operation Manual, Japan 2012

[5] Devdas Shetty, Richard A Kolk, Mechatronics System Design, Cengage Learning, USA, 2011, pp 162-164

[6] OMRON CX-Programmer Software, Ver 9.44, 2013

[7] OMRON General Purpose Encoder, Omron Corporation, 2015 